ORIGINAL ARTICLE

\title{
Socrative.Com; An Innovative Tool to Enhance Performance of Undergraduate MBBS Students in Histology Practicals
}

\author{
TAYYABA MAHMUD ${ }^{1}$, UZMA AKHTAR ${ }^{2}$, NATASHA NADEEM ${ }^{3}$, BAKHTAWAR $^{4}$ \\ ${ }^{1}$ Assistant Professor of Anatomy, CMH Lahore Medical College \& Institute of Dentistry, Lahore, NUMS, Rawalpindi, Pakistan \\ ${ }^{2}$ Professor, Department of Anatomy, CMH LMC \& IOD, Lahore Cantt, NUMS, Rawalpindi, Pakistan \\ ${ }^{3,4}$ Undergraduate medical student, CMH LMC \& IOD, Lahore Cantt, NUMS, Rawalpindi, Pakistan \\ Correspondence to Dr. Tayyaba Mahmud, Email: tayyabamahmud@hotmail.com, Phone \#+923334794840
}

\begin{abstract}
Background: Undergraduate medical students require a strong foundation in histology which is an important part of curriculum in basic sciences years. Histology is considered to be a difficult subject by the students.

Aim: To facilitate student learning, Socrative was introduced into histology practicals.

Methods: This was a comparative cross-sectional study conducted among second year MBBS students ( $n=146$ ) in histology. Socrative based activity, Space race, was introduced into histology practicals for the entire duration of module-III (10 weeks). This activity was done by the students in addition to demonstration and slide viewing under microscope. Performance of the students was assessed in histology Objective Structured Practical Examination (OSPE) and viva during module examinations. Score sheets of module-I were compared to those of module-III to assess the impact of using Socrative on academic performance. The study was approved by institutional Ethical Review Committee.

Results: The results were analyzed using Wilcoxon Signed Rank test which showed statistically significant improvement in the performance of students $(P$ value $=0.0001)$ in module-III. Moreover, $81.5 \%$ students showed improvement in academic performance after using Socrative.

Conclusion: These results show that use of Socrative assessment method as part of teaching method, improved academic performance of undergraduate medical students in histology.

Keywords: Socrative, histology, formative assessment, academic performance (MeSH words required)
\end{abstract}

\section{INTRODUCTION}

Histology, a major discipline within the medical and other life sciences curricula, is based on theoretical didactical strategies, as well as on practical training ${ }^{1}$. Histology is a subject taught to undergraduate medical and dental students. A strong knowledge of normal microarchitecture of tissues and organs is very important in order to form the basis for studying and understanding histopathology. However, students find the subject hard to understand and difficult to cover as the practice of studying microscopic structures is dull and difficult to decipher for them².

With changing times, there is a need to bring about necessary changes in the teaching system of histology in order to make it more palatable and interesting for the students. This can be done by introducing different options into the teaching methodologies e.g. use of electronic histology atlases, smart boards, virtual microscopy and more recently, student response system (SRS). For this purpose, a method should be adopted that is cost effective, user friendly, and saves time as well ${ }^{3}$.

Formative assessments can be utilized as tools to train students for final summative assessments by using similar format of testing material ${ }^{4}$. Formative assessments can be advantageous to the students as these are not part of final evaluation and hence do not impose threat or fear of exam onto the student. The student is thus able to selfassess in a more relaxed state ${ }^{5}$.

In order to make histology more interesting, and to encourage not only active, but also passive learning of the subject, it was decided to introduce an innovative practice

Received on 14-04-2021

Accepted on 02-07-2021 to the histology practicals. For this purpose, we introduced a gaming activity which was an educational online application Socrative.com, a student response system (SRS).

Socrative is available as both web-based and mobile application. Mobile application is available in teacher and student versions. Teacher needs to register and make an account, however, students need not create an account in order to attempt any activity on Socrative ${ }^{6}$. Socrative is a quiz based formative assessment tool in which teachers can design multiple choice questions, true/ false options and short answer questions ${ }^{7}$. Students can easily use it with the help of their laptops, tablets and even smart phones, however, all the activities are generated and controlled by the teacher6,8. As all students own smart phones, using a mobile phone based education application seemed feasible during histology practicals.

\section{MATERIALS AND METHODS}

This was a comparative cross-sectional study, carried out in the histology laboratory of Anatomy Department for a total duration of 22 weeks. Undergraduate students of second year MBBS $(n=110)$, were included in this study. Sample size was calculated using the following formula:

$$
n=\frac{z_{1-\frac{\alpha}{2} * \sigma^{2}}^{2}}{d^{2}}
$$

Value of standard deviation was taken from a previous study $^{9}$ (Balta and Tzafilkou 2019). Students were selected by simple random sampling. Only those students who were part of the regular session, were included. The students who joined the class later during the session, or were absent in one or both modular examinations, were 
excluded from the study. The study was approved by institutional Ethical Review Committee, reference no. 418/ERC/CMHLMC, and consent was taken from the students.

In our set up, histology practical for a specific class takes place at the designated time and day weekly. The practical class is comprised of two sessions: In the first session, a demonstration on basic comprehension of the topic based on its learning outcomes is delivered. In the second session, students view slides under the microscope, and draw relevant diagram subsequently, under the guidance of the facilitator.

For the current study, Socrative based activity was introduced on a weekly basis into the histology practicals for the entire duration of module-III (10 weeks). A short quiz for the relevant topic was prepared beforehand on Socrative for every batch of second year MBBS (maximum 50 students) visiting histology laboratory. The quizzes would be either simple true/false questions, or true/false questions based on images of slides. After the demonstration and slide viewing, students were asked to open the application on their mobile phones. SPACE RACE was used as the activity, and the students were divided into two teams: boys and girls. Both teams were assigned a specific team color. Settings of the quiz were adjusted so that all the questions were shuffled, question feedback was allowed, and final score was visible to every student at the end of the activity. These settings were adjusted to ensure that the students would be able to immediately get the feedback about their responses to the questions, as well as the final score.

At the end of module, score sheets for histology Objective Structured Practical Examination (OSPE) and viva of module-III were obtained after taking permission from relevant authorities. These score sheets were compared to score sheets of module-I to assess whether introduction of Socrative into practicals had improved their academic performance in the subject or not.

The statistical analysis of the data was performed using SPSS version 26 (IBM Corp.). Shapiro Wilks test was applied to check for normality of data. The results were analyzed using Wilcoxon Signed Rank test. Frequency and percentages were observed to look for improvement in performance. $P$ value of $<0.05$ was considered statistically significant.

\section{RESULTS}

The data obtained was negatively skewed, for both modules. Outliers were identifiable as depicted in the histograms, as shown in Figures $1 \& 2$ respectively. These outliers were either the high or low achievers of the class. Wilcoxon Signed Rank test showed that the 10 week long intervention in histology practicals, using Socrative, elicited a statistically significant change in the performance of students in the module examination $(P$ value $=0.0001)$ as depicted in Table. Overall, 88 out of 110 students $(80 \%)$ showed an improvement in their academic performance after they were introduced to Socrative based activity.

Table: Percentages of marks obtained by the students of $2^{\text {nd }}$ year MBBS in histology module examinations using Wilcoxon Signed Rank test

\begin{tabular}{|c|c|c|c|c|c|c|c|}
\hline \multirow{2}{*}{$\begin{array}{c}\text { Percentages of } \\
\text { marks obtained } \\
\text { in modules }\end{array}$} & \multicolumn{2}{|c|}{ Module-I without Socrative } & \multicolumn{3}{c|}{ Module-III with Socrative } & \multirow{2}{*}{ P value $^{*}$} \\
\cline { 2 - 8 } & Mean \pm SD & Median & IQR $^{*}$ & Mean \pm SD & Median & IQR $^{*}$ & 0.0001 \\
\cline { 2 - 9 }
\end{tabular}

* Interquartile range

Figure 1: Histogram showing the negative skewness, outliers and overall distribution of percentage of marks obtained in module-I examination

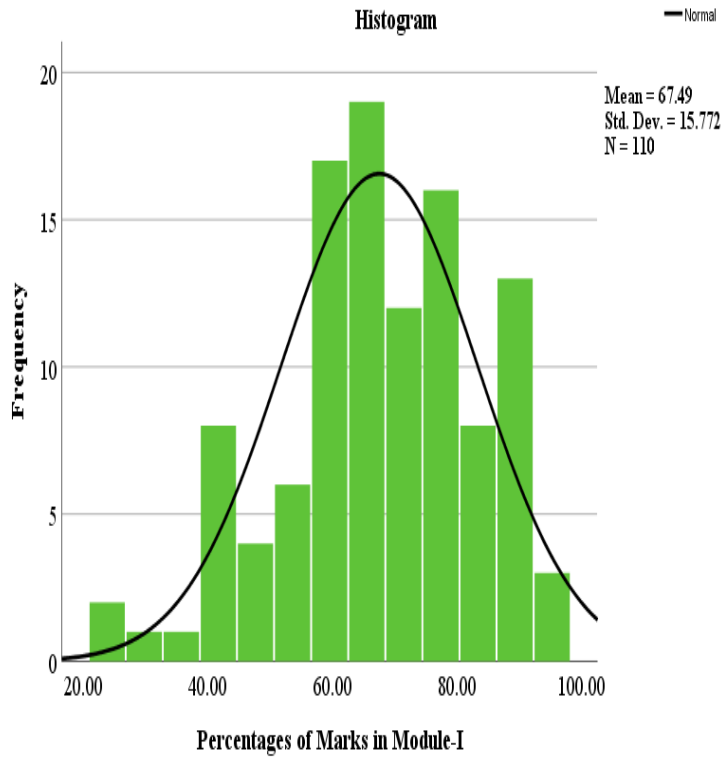

Figure 2: Histogram showing the negative skewness, outliers and overall distribution of percentage of marks obtained in module-III examination

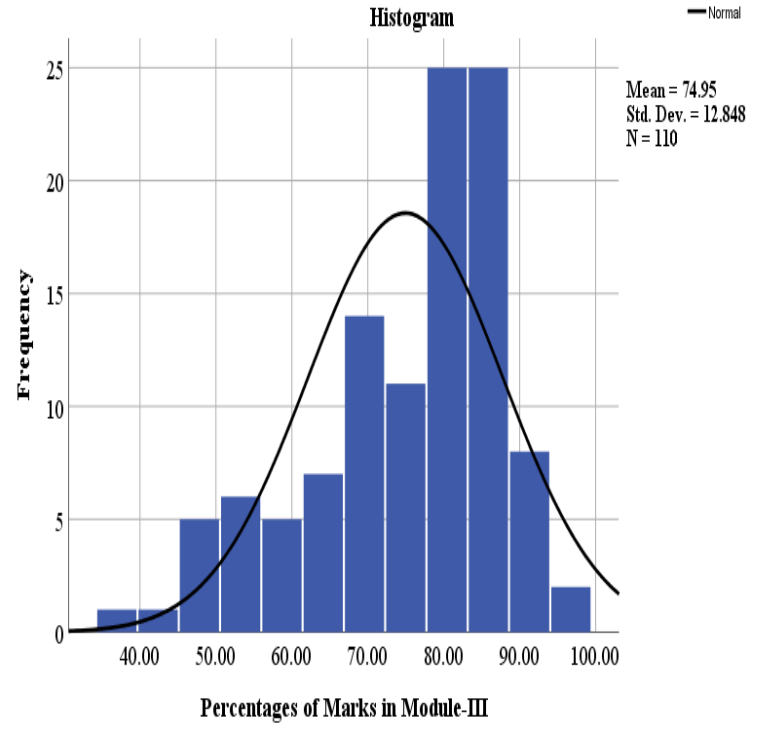




\section{DISCUSSION}

In order to make histology easier for the students, its teaching, and learning methodologies have become really dynamic over past few years ${ }^{10,11}$.

Online SRS are designed to be used with smartphones ${ }^{7}$. Mobile SRSs have benefits of utilizing new question types that are not conventionally available. Additionally, they provide convenient access and have the potential to improve learner interaction ${ }^{12}$.

Socrative, an example of SRS, is an effective tool for increasing collaborative learning ${ }^{13,14}$. In comparison to traditional SRS methods, students prefer Socrative to facilitate classroom studies ${ }^{15}$. Gamification is a technique used to facilitate formative assessment and to promote student learning, and has been shown to be more effective than traditional methods ${ }^{16}$. Gamification has the potential to promote learning, enhance collaboration and increase student engagement. Online platforms, such as Socrative, which apply game-based learning theories, have become commonly used platforms for formative assessment as a tool to promote student learning. Some researchers reviewed the benefits of using gamified training platforms for medical education, and identified Socrative as one such application used for preclinical training ${ }^{17}$.

Another study conducted to investigate three assessment systems as interactive pedagogic tools in medical education, identified Socrative as one of the favourite applications ${ }^{18}$. Socrative was found to be rated higher on both ease of use and general format enjoyment by the users ${ }^{15}$. In addition, it is cost-free and has many interactive features which make it a convenient tool for education ${ }^{19}$. Free version of socrative allows 50 students per session. This was ideal for histology practical in our set-up since each batch consists of 50 students maximum. Moreover, the students don't need to create an account on Socrative in order to attempt the quizzes.

Quizzes can be asked in a multitude of ways e.g. true/ false, MCQs and short answer questions. Quizzes can be teacher paced or even student paced, allowing sufficient time to ponder over difficult items. There is no limit to the number of questions that can be asked in a quiz. In addition, images can be incorporated into the quiz, thus making this application ideal for teaching and assessment of histology slides ${ }^{6}$.

In our study, we used either simple true/false questions, or true/false questions based on the images of histological slides. The questions covered the key points of topic under discussion, thus allowing the students to learn the basic concept of every topic thoroughly. This notably helped the students in not only understanding the slides under the microscope, but also in identifying different parts of the organs under discussion.

At the end of every session, the students were encouraged to ask questions about any aspect that was still not clear. Discussion held in this manner proved to be highly beneficial for the students. Similar to our study, it was reported that Socrative helped the students focus more on key knowledge ${ }^{20}$. Our finding was supported by another study that documented that use of SPACE RACE as the activity in Socrative was considered highly beneficial by majority of students (75\%) of ocular anatomy and histology ${ }^{19}$. Another study also stated that, majority of students find interactive gamification to be helpful in gaining better understanding and knowledge of basic histology 21 .

Our findings are supported by another study stating that digital games can engage medical students in traditionally challenging areas such as anatomy and histology. The participants found gaming to positively impact their concepts of anatomy by providing insight into their strengths and weaknesses ${ }^{22}$. Formative assessments have been in use in order to bring about a positive change in academic performance of students and eventually in the summative assessments. Socrative based formative assessments improved learning process and led to improved academic performance of students ${ }^{8,14,23}$.

According to another study, scores obtained in the final summative assessment were markedly improved when the students did self-assessment while undergoing formative assessments ${ }^{24}$. Another study reported a significant improvement in the summative scores of third year medical students after they took online formative assessments during the course of modules ${ }^{25}$. Multiple studies have documented a positive response of students to Socrative as a formative assessment tool, with $90 \%$ of students agreeing that exercises incorporating this application enhance their learning ${ }^{20}$, boost their motivation, significantly increase the learning process and improve their communication with teachers and classmates ${ }^{7,13}$. It was found to be an effective means of providing formative feedback and helps save time during lessons ${ }^{6}$.

In our study, the students' performance on the quizzes also helped in providing an indirect feedback on the teaching methodologies practiced by the facilitators. This allowed them to reflect on themselves too, thus helping in bringing about required change in their teaching patterns.

The results suggest that incorporation of an online SRS into histology practicals can not only make them more interesting for the students but can also promote learning. This practice can help in achieving the learning outcomes for the subject. Additionally, it can also provide an immediate feedback to the students on whether they had actually understood the topic or just 'believed' that they did. This will also provide an indirect feedback to the facilitators about the effectiveness of their teaching methodologies.

Limitations: Though on the whole, use of Socrative was appreciated by the students, but some issues were experienced by the students e.g. internet connectivity problems and difficulty in logging into the room at the same time as the rest of the students. This made the students anxious that they might not be able to finish the task in time. However, these issues can be addressed by reassuring the students and by contacting the IT department to ensure smooth working of internet connection.

In addition, our study conducted in the setting of a single department on one particular class. Hence the sample size was not large, though the results of our study showed statistically significant improvement in academic performance. This issue can be resolved by conducting similar study on inter-department and inter-institution level. 
This will help in further reinforcing the validity of findings of our study.

Moreover, our study focused purely on use of Socrative as SRS for formative assessment, and to increase interest of the student in histology. We did not utilize any other SRS to compare results of one SRS to another.

\section{CONCLUSION}

Use of Socrative based gaming technology brought about a positive change in the academic performance of students in histology by increasing their interest in the subject via interactive learning. The students were satisfied and favored Socrative as a tool of effective learning.

Acknowledgements: Authors are truly indebted to their colleagues/ teachers who gave guidance and helped in carrying out this experiment. Authors are grateful for the help extended by Miss Bushra, statistician, Department of Community Medicine, CMH Lahore Medical College \& Institute of Dentistry, Lahore Cantt, Pakistan, for her guidance during statistical analysis of data and interpretation of results.

Authors particularly wish to thank the students who were part of the study and fully cooperated with the authors in order to carry out the work successfully.

Declaration of Interest: The authors report no declarations of interest.

\section{REFERENCES}

1. Ahmed R, Shamim KM, Talukdar HK, Parvin S. Light microscopy for teaching-learning in histology practical in undergraduate medical education of Bangladesh- a teachers' perspective. South-East Asian Journal of Medical Education 2018; 12: 26-31. doi: 10.4038/seajme.v12i1.39

2. Johnson S, Purkiss J, Holaday L, Selvig D, Hortsch M. Learning histology - dental and medical students' study strategies. Eur J Dent Educ 2015; 19: 65-73. doi: 10.1111/eje.12104

3. Das S, Saha N, Chakraborty T, Shil A. Perception of students on histology learning method. IOSR-JDMS. 2019; 18: 11-18. doi: 10.9790/0853-1806081118

4. McCarthy J. Enhancing feedback in higher education: Students' attitudes towards online and in-class formative assessment feedback models. Act Learn High Educ. 2017; 18: 127-141. doi: 10.1177/1469787417707615

5. Rolfe I, McPherson J. Formative assessment: how am I doing? Lancet 1995; 345: 837-39. doi: 10.1016/s01406736(95)92968-1

6. Cerqueiro FF, Harrison AMM. Socrative in higher education: game vs. other uses. Multimodal Technol Interact 2019; 3: 49. doi: $10.3390 / \mathrm{mti} 3030049$

7. Rae MG, O'Malley D. Using an online student response system, Socrative, to facilitate active learning of physiology by first year graduate entry to medicine students: a feasibility study. Med Ed Publish 2017; 6: 4. doi: 10.15694/mep.2017.000004

8. Gómez-Espina R, Rodriguez-Oroz D, Chávez M, Saavedra C, Bravo MJ. Assessment of the Socrative platform as an interactive and didactic tool in the performance improvement of STEM University students. High Learn Res Commun 2019; 9: 1-18. doi: 10.18870/hlrc.v9i2.438

9. Balta $\mathrm{N}$ and Tzafilkou K. Using socrative software for instant formative feedback in physics courses. Educ Inf Technol 2019; 24: 307-23.

10. Anand AV, Pushpa NB. Innovation in histology practical demonstration: students and teachers view point. Int $\mathrm{J}$ Anat Res. 2016; 4: 2469-72. doi: 10.16965/ijar.2016.240

11. Cheng $X$, Lee KKH, Chang EY, Yang X. The "flipped classroom" approach: stimulating positive learning attitudes and improving mastery of histology among medical students. Anat Sci Educ 2017; 10: 317-27. doi: 10.1002/ase.1664

12. Gousseau M, Sommerfeld C, Gooi A. Tips for using mobile audience response systems in medical education. Adv Med Educ Pract 2016; 7: 647-52. doi: 10.2147/AMEP.S96320

13. Awedh M, Mueen A, Zafar B, Manzoor U. Using Socrative and smartphones for the support of collaborative learning. Int J Integr Technol Educ 2014; 3: 17-24. doi: 10.5121/ijite.2014.3402

14. Dakka SM. Using Socrative to enhance in-class student engagement and collaboration. Int $\mathrm{J}$ Integr Technol Educ 2015; 4: 13-9. doi: 10.5121/ijite.2015.4302

15. Guarascio AJ, Nemecek BD, Zimmerman DE. Evaluation of students' perceptions of the Socrative application versus a traditional student response system and its impact on classroom engagement. Curr Pharm Teach Learn 2017; 9: 808-12. doi: 10.1016/j.cptl.2017.05.011

16. Ismail MAA, Ahmad A, Mohammad JA, Fakri NMRM, Nor MZM, Pa MNM. Using Kahoot! as a formative assessment tool in medical education: a phenomenological study. BMC Med Educ 2019; 19: 230. doi: 10.1186/s12909-019-1658-z

17. McCoy L, Lewis JH, Dalton D. Gamification and multimedia for medical education: a landscape review. J Am Osteopath Assoc 2016; 116: 22-34. doi: 10.7556/jaoa.2016.003

18. Grzych G, Schraen-Maschke S. Interactive pedagogic tools: evaluation of three assessment systems in medical education. Ann Biol Clin (Paris) 2019; 77: 429-35. doi: 10.1684/abc.2019.1464

19. Luesma MJ, Cantarero I, Artal-Sevil JS. Space race: An interactive digital tool in the classroom. Are you ready? Proc 2018; 2: 1319. doi: 10.3390/proceedings2211319

20. Al Sunni A, Latif R. Determining the effectiveness of a cell phone-based student response system. J Taibah Univ Med Sci 2020; 15: 59-65. doi: 10.1016/j.jtumed.2019.12.002

21. Felszeghy $S$, Pasonen-Seppänen $S$, Koskela $A$, et al. Using online game-based platforms to improve student performance and engagement in histology teaching. BMC Med Educ 2019; 19: 273. doi: 10.1186/s12909-019-1701-0

22. Janssen A, Shaw T, Goodyear P, Kerfoot BP, Bryce D. A little healthy competition: using mixed methods to pilot a teambased digital game for boosting medical student engagement with anatomy and histology content. BMC Med Educ 2015; 15: 173. doi: 10.1186/s12909-015-0455-6

23. Balta N, Perera-Rodríguez VH, Hervás-Gómez C. Using Socrative as an online homework platform to increase students' exam scores. Educ Inf Technol 2018; 23: 837-50. doi: 10.1007/s10639-017-9638-6

24. Oellermann SW, Merwe AVD. Can using online formative assessment boost the academic performance of business students? An empirical study. Int J Educ Sci 2015; 8: 535-46. doi: 10.1080/09751122.2015.11890275.

25. Azam F, Shaheen A, Irshad K, Javed N, Ata M. Trends of undergoing formative assessment in undergraduate medical students. JSTMU 2019; 1: 21-6. doi: 10.32593/jstmu/Vol1.Iss1.34. 